\title{
RANCANGAN PENGOLAHAN BATU ANDESIT UNTUK MEMENUHI STANDAR INDUSTRI INDONESIA
}

\section{ANDESITE PROCESSING DESIGN TO FULFILL INDONESIAN INDUSTRIAL STANDARDS}

\author{
MD. Amdi ${ }^{1}$, Mukiat ${ }^{2}$, YB. Ningsih ${ }^{3}$ \\ ${ }^{1-3}$ Jurusan Teknik Pertambangan, Fakultas Teknik, Universitas Sriwijaya \\ J1. Raya Palembang-Prabumulih Km.32 Inderalaya Sumatera Selatan, Indonesia \\ e-mail: 1 meutiadianiamdi@gmail.com, ${ }^{2}$ mukiats@yahoo.com, ${ }^{3}$ y.bayuningsih@gmail.com
}

\section{ABSTRAK}

Pembangunan infrastruktur yang terus meningkat memberi pengaruh pada kebutuhan material konstruksi. Material konstruksi yang dibutuhkan salah satunya batu split. Batu split dapat berasal dari andesit. Cadangan andesit di daerah Tanjung Enim, perlu dimanfaatkan sebagai material konstruksi. Akan tetapi, berdasarkan penelitian sebelumnya, produk pengolahan dari pabrik peremukan batuan andesit di PT Bukit Asam, Tbk. belum memenuhi standar sebagai material konstruksi beton. Penelitian ini bertujuan untuk mendesain alur pengolahan baru sehingga kualitas hasil pengolahan dapat memenuhi kualitas standar industri Indonesia serta menganalisis biaya yang akan dikeluarkan dari alur baru tersebut. Penelitian dimulai dengan melakukan perancangan serta menghitung persentase ukuran produk hasil pengolahan dari unit crushing plant yang dilakukan menggunakan kurva closed side setting jaw crusher. Selanjutnya dihitung total biaya pengolahan dan memperkirakan akibat yang akan diperoleh perusahaan apabila menginvestasikan alat crushing plant baru. Berdasarkan penelitian didapatkan bahwa ukuran produk pemecahan sangat beragam, sehingga pada alur pengolahannya diperlukan secondary crusher. Batuan andesit akan direduksi ukurannya dari $700 \mathrm{~mm}$ menjadi $200 \mathrm{~mm}$ dengan menggunakan primary jaw crusher. Kemudian direduksi kembali menjadi $70 \mathrm{~mm}$ menggunakan secondary jaw crusher. Penambahan deck pada vibrating screen juga diperlukan agar dihasilkan produk dengan empat fraksi yakni 0-10mm, 1020mm, 20-50mm, dan 50-70mm. Biaya pengolahan yang akan dikeluarkan dari alur tersebut adalah Rp 1.490.018,74/jam. Apabila perusahaan melakukan investasi alat crushing plant baru maka, perusahaan akan memperoleh keuntungan sebesar Rp 2.271.582.678/bulan. Hasil penelitian menunjukkan perlunya pembangunan unit crushing plant baru agar produk hasil pengolahan memenuhi standar. Pembangunan unit crushing plant ini juga dinyatakan layak secara ekonomi.

Kata kunci: Crushing plant, Andesit, Standar Industri Indonesia, Biaya Pengolahan

\section{ABSTRACT}

The increase in infrastructure development gives an impact on the need for construction materials. One of the construction materials is split that becomes from andesite. The existence of andesite in Tanjung Enim needs to be utilized optimally. But based on the previous research, the andesite processing result does not match with the standards. This study aims to design a new processing flow and analyze the processing cost so that the quality will match the standard. This study was started by preparing a new processing design and calculating the percentage of the product size using the curve of the jaw crusher's closed-side setting produced from the new design. The processing costs will be calculated too, and the consequences will be known if the company decides to invest in a new crushing plant. From research, the split size is bigger enough and secondary crushing is needed. Andesite size will be reduced by jaw crusher from $700 \mathrm{~mm}$ to $200 \mathrm{~mm}$. And reduced back to $70 \mathrm{~mm}$ by secondary jaw crusher. The vibrating screen's deck addition is also needed to produce four fraction products, namely 0-10 mm, 10-20mm, 20-50mm, and 50-70mm. The processing cost that will be incurred from this flow is IDR 1.490.018,74/hour. If the company invests in a new crushing plant, the company will get a profit of IDR 2.271.582.678/month. The results show that a new crushing plant needs to be built, so split size complies with the standards. And also, this decision is economically feasible.

Kata kunci: Crushing plant, Andesite, Indonesian Industry Standards, Processing Costs 


\section{PENDAHULUAN}

Pembangunan infrastruktur yang terus meningkat memberi dampak besar pada kebutuhan akan material konstruksi. Batu split yang dimanfaatkan sebagai material konstruksi tentunya sangat dibutuhkan. Batu split merupakan material pengisi (agregat kasar) dalam campuran beton dengan komposisi terbesar diantara campuran lainnya, seperti semen dan pasir. Apabila diinginkan beton yang dihasilkan berkualitas baik, tentunya perlu ada campuran serta ukuran batu split yang sesuai dengan standar mutu beton.

Salah satu jenis batuan yang dapat dijadikan sebagai batu split adalah andesit. Adanya cadangan andesit di daerah kuasa penambangan PT Bukit Asam, Tbk perlu dimanfaatkan serta dikelola secara optimal agar dapat dijadikan sebagai material konstruksi. Mengingat dibutuhkannya lebih banyak pemasok batu andesit untuk menunjang pembangunan yang ada.

Untuk menghasilkan beton yang berkualitas tinggi, ukuran dari batu split yang digunakan harus memenuhi ukuran yang sesuai dengan standar industri Indonesia. Agar ukuran tersebut terpenuhi, batu andesit setelah ditambang perlu direduksi ukurannya melalui beberapa tahapan pengolahan di unit crushing plant. Dari penelitian sebelumnya, batu andesit dari hasil pengolahan unit crushing plant di PT Bukit Asam, Tbk. belum memenuhi standar yang ada, mengingat batu andesit hasil pengolahan tersebut hanya untuk memenuhi kebutuhan internal tambang batubara [1]. Adanya kajian ini dirasa perlu agar unit crushing plant yang ada mampu menghasilkan ukuran batu andesit yang sesuai untuk campuran beton menurut standar industri Indonesia yang ditetapkan.

Tujuan dilakukannya penelitian ini ialah mendesain alur pengolahan untuk unit crushing plant batu andesit sehingga kualitas hasil pengolahan dapat memenuhi kualitas standar industri Indonesia. Selain itu, menganalisis biaya pengolahan yang akan dikeluarkan dari alur baru tersebut.

Alur kerja pengolahan akan mempengaruhi gradasi hasil pengolahan. Untuk membuat campuran beton yang baik, faktor yang perlu diperhatikan ialah gradasi atau besar butir dari agregat yang digunakan dalam campuran beton [2]. Persyaratan yang diatur standar nasional Indonesia untuk gradasi agregat kasar dinyatakan dalam modulus kehalusan. Nilai modulus kehalusan didapatkan dari uji ayakan. Modulus kehalusan merupakan indeks yang menunjukkan kasar atau halusnya agregat dalam rentang ukuran tertentu (fraksi). Semakin besar nilai fineness modulus yang ditunjukkan oleh fraksi agregat, maka akan semakin besar ukuran butir atau gradasi dari agregat tersebut [3].
Untuk menghasilkan produk hasil pengolahan yang sesuai dengan standar industri Indonesia, maka perlu ditinjau kembali alur kerja pada unit crushing plant. Dengan mengadaptasi proses penghancuran dengan feed yang tersedia dan produk yang diinginkan, kualitas produk yang dihancurkan dapat dioptimalkan bersama dengan operasi crusher [4].

Unit crushing plant merupakan kumpulan alat yang bekerja secara berkesinambungan mulai dari awal proses pemecahan hingga akhir pemecahan, sehingga tidak dapat dipisahkan antara satu komponen dengan lainnya. Unit ini dimulai dari hopper, kemudian akan diumpankan grizzly feeder untuk masuk ke jaw crusher sebagai alat penghancuran tahapan pertama. Setelah itu, tahapan dilanjutkan dengan penghancuran kedua dan material pecahan akan ditampung di gudang batu. Di gudang batu, material pecahan akan digerus menggunakan cone crusher sehingga dihasilkan material yang cukup kecil. Produk pecahan tersebut akan didistribusikan oleh belt conveyor dan dibawa menuju vibrating screen untuk dipisahkan [5].

Proses pemecahan atau reduksi ukuran batuan perlu dilakukan secara bertahap karena keterbatasan kemampuan alat pemecahan dalam mereduksi ukuran batuan dari yang besar hingga menjadi ukuran kecil yang dikehendaki [6].

Dari penelitian sebelumnya diketahui bahwa ada tiga langkah utama dalam mendesain unit crushing plant yang baik, yakni desain alur yang dipilih, pemilihan komponen alat crushing plant serta susunan desain. Dua langkah pertama ditentukan oleh target produksi dan tolak ukur desain, sedangkan susunan desain dipengaruhi oleh pengalaman serta berbagai masukan dari berbagai pihak. Perancangan crushing plant baru harus mengetahui cara-cara membuat plant sederhana dan ekonomis dalam pengoperasiannya. Beberapa modifikasi serta menambah unit plant dapat dibenarkan dengan pengurangan biaya operasi [7].

Lokasi ideal plant seharusnya berada di dekat kota yang sedang berkembang atau kota besar untuk memenuhi permintaan batu dan pada saat yang sama dekat sumber batu yang akan dihancurkan. Proses yang terlibat dalam penghancuran batu-batu berukuran besar menjadi berbagai ukuran tergantung pada persyaratan di sektor permintaan. Ada banyak variasi dalam jenis pemilihan alat penghancur tergantung pada lokasi geografis, jenis permintaan untuk produk batu pecah, kedekatan dengan daerah perkotaan, jenis bahan baku, ketersediaan pabrik dan mesin lokal [8].

Dalam melakukan perancangan ulang alur kerja pengolahan terdapat beberapa variabel yang perlu diubah. Penelitian sebelumnya memberikan penilaian secara teknis dari unit crushing plant sehingga didapatkan penyebab target produksi yang belum terpenuhi dan juga 
memberikan alternatif perubahan diagram pengolahan sehingga produksi dapat dipenuhi. Dalam mengevaluasi kinerja unit peremukan dilakukan perubahan diagram pengolahan dengan mengubah closed side setting serta mengupayakan pengurangan waktu kerja yang tidak maksimal. Selain itu dari evaluasi tersebut juga diberikan distribusi produk hasil pengolahan memakai grafik hubungan antara closed side setting dengan besarnya persentase produk yang dapat lolos [9].

Untuk menjamin berlangsungnya proses produksi, maka diperlukan biaya. Biaya pada unit pengolahan dapat dikelompokkan menjadi dua, yakni biaya kepemilikan (owning cost) alat serta biaya operasional (operating cost) alat [10]. Biaya kepemilikan adalah biaya yang harus ditangguhkan atas kepemilikan alat-alat berat. Sedangkan biaya operasional alat adalah biaya yang keluar saat alat beroperasi.

Penelitian untuk menghitung biaya pengolahan telah dilakukan sebelumnya. Perhitungan biaya pengolahan untuk mengetahui kelayakan pada proses penambangan serta pengolahan batuan basalt menjadi bahan baku split pada areal Bukit Karang Putih PT Semen Padang. Hasil akhir yang didapatkan merupakan kriteria dalam investasi penambangan dan pengolahan basalt berdasarkan NPV, IRR dan payback period yang menyatakan layak atau tidaknya penambangan dan pengolahan dilakukan [10].

\section{METODE PENELITIAN}

Penelitian ini dilakukan di lokasi penambangan batu andesit PT Bukit Asam, Tbk., UPTE, Sumatera Selatan. Penelitian dimulai pada bulan Maret 2020 hingga April 2020 di site penambangan Tambang Air Laya.

Tahapan penelitian diawali dengan observasi lapangan. Dari tahapan ini, aktivitas pengolahan batu andesit yang dilakukan PT Bukit Asam, Tbk. dapat diketahui. Tahapan berikutnya yang dilakukan adalah pengambilan data penelitian yang terbagi menjadi data primer dan data sekunder. Data Primer pada penelitian ini berupa konsumsi listrik, pelumas dan gemuk di unit crushing plant. Konsumsi listrik untuk unit crushing plant didapatkan dengan mengamati spesifikasi daya komponen alat crushing plant dari ruang operator. Sedangkan konsumsi gemuk dan pelumas didapatkan melalui pengamatan dan informasi dari mekanik saat melakukan perawatan rutin. Data sekunder pada penelitian ini meliputi:

a. Spesifikasi alat pengolahan di unit crushing plant

Spesifikasi alat memberikan informasi penting alat yang dapat digunakan ketika menghitung produktivitas aktual dari unit crushing plant

b. Modulus kehalusan (fineness modulus) fraksi batuan $0-20 \mathrm{~mm}$
Nilai fineness modulus pada fraksi 0-20 $\mathrm{mm}$ diperlukan sebagai informasi mengenai kualitas produk pengolahan unit peremukan batuan andesit di PT Bukit Asam, Tbk.

c. Jumlah batu andesit yang dibutuhkan sebagai penunjang tambang Banyaknya kebutuhan akan batu andesit hasil pengolahan digunakan untuk memperkirakan jumlah batu andesit dari unit crushing plant yang dapat dijual dan dipasarkan.

d. Biaya pembelian alat crushing plant, besar pajak, bunga dan asuransi

Biaya pembelian alat crushing plant, tarif biaya pajak, bunga serta tarif asuransi digunakan untuk perhitungan biaya kepemilikan unit crushing plant.

Tahapan selanjutnya adalah pengolahan data. Tahapan pengolahan data diawali dengan membandingkan nilai modulus kehalusan hasil pengolahan di PT Bukit Asam, Tbk dengan standar nasional Indonesia dan standar industri Indonesia yang memiliki rentang 6-7,10. Persyaratan nilai modulus kehalusan ini merupakan acuan yang harus terpenuhi ketika batu andesit hasil pengolahan akan dimanfaatkan sebagai material pengisi beton (agregat). Nilai modulus kehalusan material pengisi beton untuk batu pecah harus memenuhi persyaratan yang mengacu pada standar industri Indonesia 0052-80 dan juga standar nasional Indonesia S-04-1989-F. Ketika modulus kehalusan belum terpenuhi, maka dilakukan perancangan alur kerja pengolahan.

Apabila perancangan alur kerja dibutuhkan, maka tahapan yang diperlukan ialah meninjau kembali alur kerja pengolahan yang ada. Peninjauan dilakukan dengan terlebih dahulu melihat nilai modulus kehalusan dari hasil uji ayakan. Ketika nilai modulus kehalusan dari material lebih kecil dari standar, maka gradasi atau ukuran butir material tersebut kecil dan halus. Material ini dapat disebut sebagai agregat halus. Sebaliknya apabila nilai modulus kehalusan material tersebut lebih besar dari standar, maka ukuran butir batu andesit hasil pengolahan masih besar apabila digunakan sebagai material pengisi (agregat) dalam beton, sehingga batu andesit hasil pengolahan yang ada perlu dikecilkan (direduksi) kembali.

Agar dihasilkan produk pengolahan yang lebih kecil, diperlukan unit secondary crushing. Pemilihan jenis alat untuk secondary crushing harus disesuaikan dengan kebutuhan perusahaan saat ini.

Dalam penggunaan unit crusher, terdapat istilah open side setting dan closed side setting. Open side setting menyesuaikan closed side setting dari primary jaw crusher sedangkan closed side setting dari pada crusher yang akan digunakan diatur sesuai dengan ukuran produk pengolahan andesit terbesar yang akan dihasilkan. 
Setelah perancangan alur kerja dilakukan, perlu dilakukan perhitungan persentase masing-masing produk pengolahan yang direncanakan akan dihasilkan dari alur ini. Perkiraan persentase produk hasil pengolahan jaw crusher dapat diketahui dari grafik hubungan antara closed side setting jaw crusher dengan banyaknya persentase produk yang dapat lolos (Gambar 1) [11]

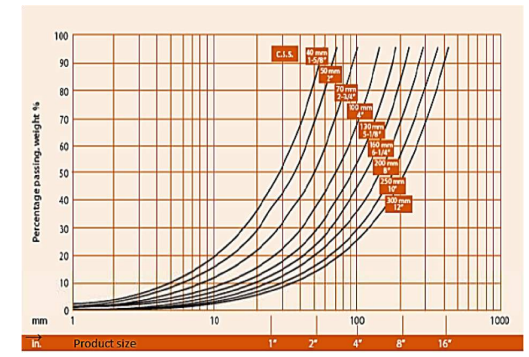

Gambar 1. Grafik hubungan antara closed side setting jaw crusher dengan persentase produk lolos

Persentase produk hasil pemecahan jaw crusher dapat dibaca berdasarkan grafik dengan menghubungkan ukuran produk yang ingin dihasilkan dalam satuan $\mathrm{mm}$ atau inci dengan kurva closed side setting pada gambar dan buat garis yang menghubungkan keduanya. Kemudian persentase produk tersebut dapat diketahui dengan menarik garis horizontal dari hubungan garis sebelumnya.

Setelah persentase produk hasil pengolahan diketahui, tonase produk yang dihasilkan juga akan diketahui. Ketika produk hasil pengolahan dapat diperkirakan, maka dapat juga diperkirakan jumlah produk yang bisa dipasarkan. Untuk mengestimasikan jumlah produk pengolahan batuan andesit yang dapat dikomersilkan, perlu mengurangkan produksi absolut unit pengolahan dengan banyaknya batuan andesit hasil pengolahan sebagai penunjang tambang.

Untuk dapat menghasilkan produk pengolahan yang siap untuk dijual, perlu diperhitungkan biaya yang harus dikeluarkan perusahaan pada unit crushing plant. Biaya pada unit pengolahan tersebut terdiri dari biaya kepemilikan dan biaya operasional [12].

Untuk mengestimasikan besarnya biaya kepemilikan, maka perlu menjumlahkan komponen biaya kepemilikan. Biaya kepemilikan terdiri dari:

1. Biaya Penyusutan (Depresiasi)

Penyusutan (depresiasi) adalah hilangnya biaya modal untuk pembelian alat berat yang diakibatkan oleh kerusakan pada alat, pengurangan komponen alat dan penurunan harga alat dipasaran. Penurunan nilai alat berat tersebut berkaitan dengan lamanya pemakaian alat [13].
Biaya depresiasi dapat dihitung dengan Pers. (1) berikut.

Depresiasi $=\underline{\text { Harga mesin-(Harga ban }) \text {-Harga sisa (Rupiah) }}$

Apabila alat tidak menggunakan ban, maka harga ban ditiadakan.

2. Bunga Modal, Pajak dan Asuransi

Perhitungan bunga modal, pajak serta asuransi dapat disatukan menggunakan Pers. (2) berikut.

Total $=\frac{\text { Annual Investment } x \text { Harga Alt } x \text { Tarif Own Cost }}{\text { Jam Pemaksian per Tahun }}$

Perhitungan annual investment (biaya annual tahunan rata-rata) dengan nilai sisa alat, dapat menggunakan Pers. (3) sebagai berikut [14].

$\mathrm{Ia}=(\mathrm{P}-\mathrm{Sv})(\mathrm{A} / \mathrm{P} . \mathrm{i} \%, \mathrm{n})+\mathrm{Sv}(\mathrm{A} / \mathrm{F} . \mathrm{i} \%, \mathrm{n})$

Keterangan:

Ia = biaya annual tahunan rata-rata ( $\mathrm{Rp} /$ Tahun)

$\mathrm{P} \quad=$ harga alat berat $(\mathrm{Rp})$

$\mathrm{Sv}=$ nilai sisa alat berat $(\mathrm{Rp})$

$\mathrm{A} / \mathrm{P}=$ nilai waktu uang di masa sekarang menjadi tahunan

$\mathrm{A} / \mathrm{F}=$ nilai waktu uang di masa yang akan datang menjadi tahunan

$\mathrm{i} \quad=$ tingkat suku bunga $(\%)$

$\mathrm{n} \quad=$ lamanya investasi dalam tahun

Menentukan tarif bunga, pajak dan asuransi berbeda tiap negara. Besarnya tarif bunga, bergantung pada tingkat suku bunga kredit yang berlaku saat itu. Sedangkan tarif dalam pajak serta asuransi ditetapkan berdasarkan nilai sisa alat [15].

Tarif owning cost untuk bunga modal biasanya $6 \%$. Untuk pajak besarnya antara 1,5\% - 2\%. Sedangkan untuk asuransi besarnya $1 \%-3 \%$ [16]

Untuk mendapatkan besarnya biaya operasional, maka perlu menjumlahkan komponen biaya operasional. Biaya operasional terdiri dari:

1. Listrik

Biaya listrik dapat dihitung dengan Pers. (4) berikut:

Biaya Listrik = Kebutuhan listrik/jam x Harga listrik/kwh

2. Minyak Pelumas dan Gemuk

Tiap-tiap komponen alat berat akan melakukan pekerjaan yang berbeda pula. Hal ini tentunya mengakibatkan komponen alat tersebut memiliki kebutuhan bahan pelumas serta gemuk yang berbeda pula [14]. Untuk menghitung biaya pelumas dan gemuk dapat menggunakan Pers. (5) berikut:

Biaya Pelumas $=$ Kebutuhan pelumas $\mathrm{x}$ Harga pelumas $/$ liter 
3. Perbaikan atau Reparasi

Untuk menghitung biaya perbaikan alat dapat menggunakan Pers. (6) berikut:

Biaya reparasi $=\frac{\text { Faktor perbaikan } \mathrm{x} \text { (Harga Mesin-Harga Ban) }}{\text { umur Kegunaan Alat (Iam) }}$

4. Gaji Operator

Gaji operator per jam-nya dapat dihitung dengan menggunakan Pers. (7) sebagai berikut:

Gaji Operator $=\underline{\text { Upah Operator }+ \text { Pembantu per Bulan (Rupiah) }}$

Setelah pengolahan data, dilakukan tahapan analisis data. Analisis ini dilakukan dengan mengetahui nilai modulus kehalusan hasil pengolahan terlebih dahulu. Ketika standar modulus kehalusan belum bisa dipenuhi, maka alur kerja pengolahan perlu dianalisis kembali. Biaya pengolahan untuk alur kerja yang baru perlu dianalisis sehingga menghasilkan keuntungan untuk perusahaan.

Setelah pengolahan dan analisis data, kemudian lakukan pengambilan kesimpulan. Dalam proses pengambilan kesimpulan perlu ditujukan untuk menjawab tujuan dari dilakukannya penelitian ini.

\section{HASIL DAN PEMBAHASAN}

Proses penambangan batu andesit di PT Bukit Asam, Tbk. dilakukan di quarry dengan terlebih dahulu melakukan pembongkaran batu andesit yang massive dengan pemboran serta peledakan. Dari aktivitas peledakan ini didapatkan batu andesit yang berbentuk boulder atau bongkahan. Boulder dapat langsung dimanfaatkan untuk kebutuhan penunjang tambang atau diproses di unit crushing plant untuk direduksi ukuran. Ketika dilakukan pengolahan boulder terlebih dahulu, boulder tersebut merupakan umpan pengolahan untuk unit peremukan. Unit crushing plant batuan andesit PT Bukit Asam, Tbk saat ini memiliki alur kerja seperti Gambar 2 berikut.

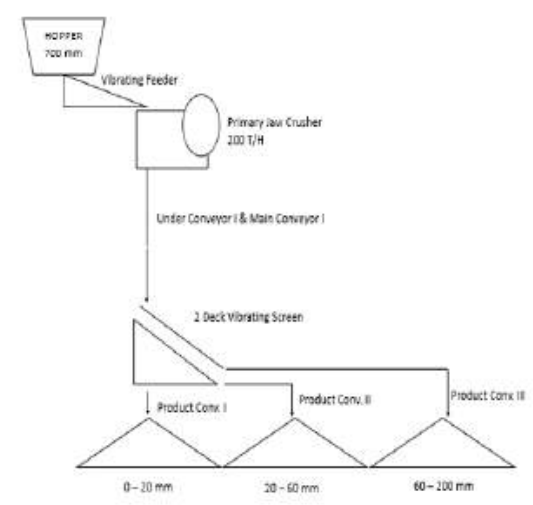

Gambar 2. Flowchart pengolahan batu andesit di PT Bukit Asam, Tbk
Kualitas batu andesit yang dihasilkan dari flowchart pengolahan batuan andesit yang ada di PT Bukit Asam, Tbk. saat ini belum dapat memenuhi standar baku mutu beton yang ditetapkan dalam SNI dan SII. Penyebabnya ialah nilai fineness modulus yang diperoleh dari uji ayakan yang dilakukan pada penelitian sebelumnya didapatkan sebesar 7,66 melebihi kriteria yang ditetapkan yakni harus berada pada batas 6-7,10 [1]. Nilai modulus kehalusan yang melewati batas tersebut, yakni berada diluar standar menunjukkan produk pengolahan dari unit peremukan yang ada, masih memiliki ukuran butir yang cukup besar. Agar dihasilkan ukuran butir produk pengolahan yang memenuhi kriteria, maka dibutuhkan tahap pengecilan ukuran lanjutan menggunakan secondary crusher.

Belum terpenuhinya kualitas batu andesit hasil pengolahan menurut SNI dan SII di PT Bukit Asam, Tbk. menunjukkan batu andesit yang dihasilkan belum dapat dijadikan sebagai material pengisi beton yang baik. Untuk itu, diperlukan desain ulang agar alur kerja pengolahan dapat menghasilkan produk pengolahan yang memenuhi standar yang telah ditetapkan. Kondisi unit crushing plant yang sudah ada hanya memungkinkan untuk menghasilkan batu andesit dengan ukuran saat ini. Maka akan lebih efektif apabila perusahaan membangun unit crushing plant baru dan produk pengolahan yang memenuhi standar industri Indonesia berasal dari unit pengolahan ini. Tidak hanya menambah alat peremukan kedua (secondary crushing), diperlukan juga vibrating screen dengan 3 buah deck agar produk terpisah dengan spesifikasi yang umumnya ada di pasaran.

Pemilihan unit secondary crushing yang dirasa cocok ialah dengan menggunakan secondary jaw crusher. Hasil produk pengolahan andesit yang diharapkan ialah tidak begitu halus. Kualitas produk dapat dioptimalkan dengan tetap menggunakan jaw crusher pada tahapan secondary, mengingat unit crushing plant di PT Bukit Asam, Tbk. harus dapat menghasilkan produk yang diperlukan untuk kebutuhan penunjang tambang batubara yang ada.

Alur pengolahan yang direncanakan pada unit crushing plant II dimulai sesaat setelah material dari dump truck ditumpahkan ke dalam hopper. Batu andesit yang masih berbentuk bongkah akan mengalami reduksi pertama menggunakan primary jaw crusher. Setelah itu, batu andesit akan diarahkan untuk masuk tahap reduksi kedua menggunakan secondary jaw crusher. Batu andesit yang sudah terreduksi, akan dibawa oleh belt conveyor menuju vibrating screen untuk dipisahkan. Digunakan vibrating screen dengan triple deck agar fraksi produk yang dihasilkan terbagi menjadi empat. Produk pengolahannya terdiri dari batu andesit dengan ragam ukuran mulai dari 0-10mm, 10-20mm, 20-50mm, dan 50-70mm.

Perencanaan pembangunan unit crushing plant kedua juga tengah direncanakan oleh PT Bukit Asam, Tbk. Unit crushing plant kedua ini direncanakan akan 
memiliki alat secondary crushing berupa secondary jaw crusher. Gambar 3 menunjukkan bagan alir rencana pengolahan di unit crushing plant II.

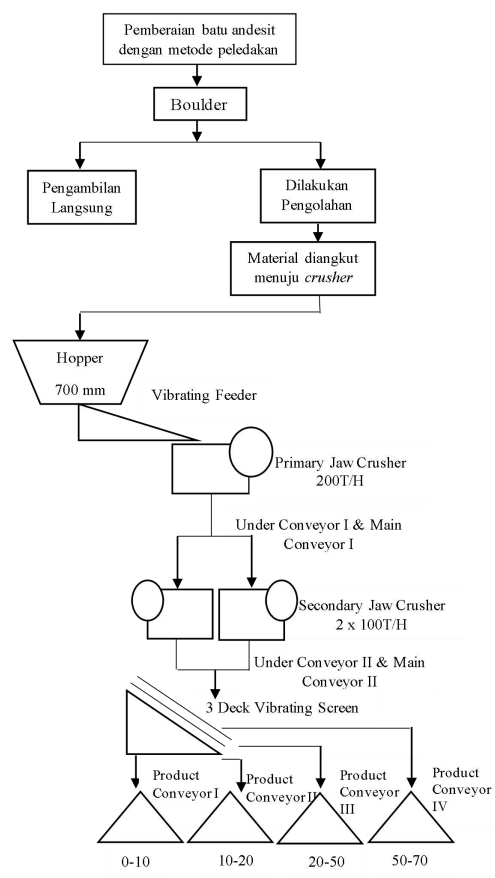

Gambar 3. Flowchart rencana pengolahan batuan andesit pada unit crushing plant II

Unit crushing plant II direncanakan memiliki kapasitas 200 ton/jam. Dalam perkiraan persentase produk hasil pengolahan dipakai kapasitas teoritis ini, karena kondisi alat yang baru sehingga hasil pengolahan pada unit crushing plant dianggap $100 \%$ dan tidak terjadi losses. Artinya persentase yang akan direncanakan menunjukkan keseluruhan umpan yang masuk sebanyak 200 ton/jam akan menghasilkan produk sebesar 200 ton/jam juga.

Batu andesit yang ingin dihasilkan dari proses pengolahan memiliki ukuran maksimal $70 \mathrm{~mm}$. Oleh karena itu, pada unit jaw crusher kedua perlu direncanakan agar pengaturan closed side setting memiliki bukaan sebesar $70 \mathrm{~mm}$.

Untuk memperkirakan persentase tiap-tiap produk yang dihasilkan dari pemecahan jaw crusher dapat menggunakan grafik hubungan antara closed side setting jaw crusher dengan banyaknya persentase produk yang dapat lolos. Dengan menggunakan grafik pada gambar 1, persentase produk pengolahan yang diinginkan dari pengaturan jaw crusher tersebut ditunjukkan pada Gambar 4.

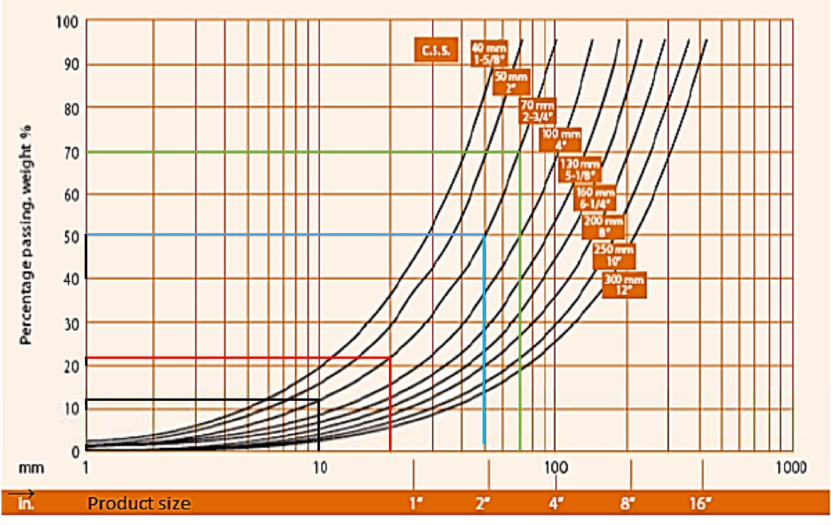

Gambar 4.Hubungan antara CSS 700 mm jaw crusher dengan persentase produk yang dapat lolos

Berdasarkan Gambar 4, diperoleh probabilitas persentase produk pengolahan yang lolos dengan CSS $700 \mathrm{~mm}$. Garis berwarna yang terdapat di dalam grafik tersebut, memperlihatkan persentase kelolosan produk pengolahan yang diharapkan dari pemecahan secondary jaw crusher. Tiap-tiap warna melambangkan persentase ukuran maksimum fraksi produk yang diharapkan.

Perkiraan persentase masing-masing produk ditampilkan pada Tabel 1.

Tabel 1. Distribusi fraksi produk pengolahan dengan CSS 700mm

\begin{tabular}{|l|r|}
\hline \multicolumn{1}{|c|}{ Fraksi } & Rentang Persentase Produk (\%) \\
\hline $0-10 \mathrm{~mm}$ & $1,5-12,5$ \\
\hline $10-20 \mathrm{~mm}$ & $12,5-22,0$ \\
\hline $20-50 \mathrm{~mm}$ & $22,0-50,0$ \\
\hline $50-70 \mathrm{~mm}$ & $50,0-70,0$ \\
\hline
\end{tabular}

Melalui pengolahan data dengan mengambil nilai tengah persentase dari tiap-tiap fraksi pengolahan diperoleh probabilitas persentase tiap-tiap fraksi (Tabel 2).

Tabel 2. Persentase fraksi produk pengolahan rencana unit peremukan II

\begin{tabular}{|l|r|r|}
\hline \multicolumn{1}{|c|}{ Fraksi } & \multicolumn{1}{|c|}{$\begin{array}{c}\text { Nilai Tengah } \\
\text { Persentase Fraksi }\end{array}$} & $\begin{array}{c}\text { Persentase Fraksi } \\
\text { Produk Rencana }\end{array}$ \\
\hline $0-10 \mathrm{~mm}$ & 7,00 & 5,82 \\
\hline $10-20 \mathrm{~mm}$ & 17,25 & 14,35 \\
\hline $20-50 \mathrm{~mm}$ & 36,00 & 29,94 \\
\hline $50-70 \mathrm{~mm}$ & 60,00 & 49,90 \\
\hline Jumlah & 120,25 & 100,00 \\
\hline
\end{tabular}

Berdasarkan Tabel 2, didapatkan persentase dari masingmasing produk yang direncanakan dapat diproduksi dari unit pengolahan II (Tabel 3). 
Tabel 3. Persentase produk rencana unit pengolahan II

\begin{tabular}{|l|r|}
\hline \multicolumn{1}{|c|}{ Fraksi } & \multicolumn{1}{|c|}{ Persentase Produk (\%) } \\
\hline $0-10 \mathrm{~mm}$ & 5,82 \\
\hline $10-20 \mathrm{~mm}$ & 14,35 \\
\hline $20-50 \mathrm{~mm}$ & 29,94 \\
\hline $50-70 \mathrm{~mm}$ & 49,90 \\
\hline
\end{tabular}

Jumlah feed yang diperkirakan masuk pada unit crushing plant II adalah sebanyak 200 ton/ jam. Dari persentase yang telah didapatkan sebelumnya, berikut tabel 4 menunjukkan jumlah masing-masing produk batu andesit yang akan dihasilkan.

Tabel 4. Jumlah masing-masing fraksi unit pengolahan II dalam ton/jam

\begin{tabular}{|l|r|}
\hline \multicolumn{1}{|c|}{ Fraksi } & \multicolumn{2}{|c|}{ Produk (Ton/Jam) } \\
\hline $0-10 \mathrm{~mm}$ & 11,64 \\
\hline $10-20 \mathrm{~mm}$ & 28,69 \\
\hline $20-50 \mathrm{~mm}$ & 59,88 \\
\hline $50-70 \mathrm{~mm}$ & 99,79 \\
\hline
\end{tabular}

Berdasarkan uraian diatas, berikut gambar 5 menunjukkan diagram alur kerja pengolahan tiap-tiap komponen unit pengolahan.

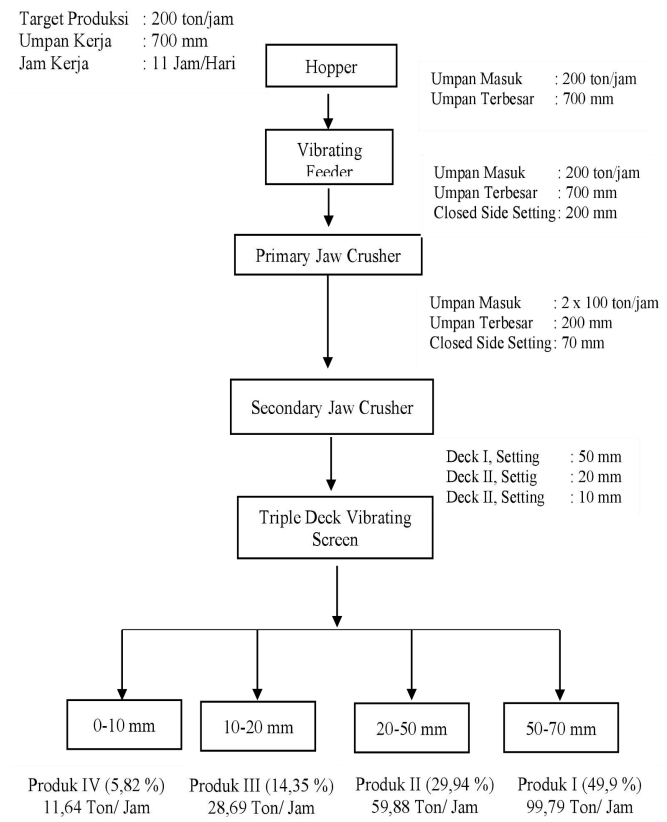

Gambar 5. Diagram alur kerja pengolahan tiap-tiap komponen uniT pengolahan

Perencanaan unit pengolahan batu andesit yang baru diharapkan dapat meningkatkan produksi. Apabila alternatif pembangunan unit crushing plant baru dipilih, akan lebih baik batu andesit hasil pengolahan unit ini dapat dikomersilkan.
Untuk dapat memperkirakan banyaknya produk pengolahan yang dapat diikomersilkan, diperlukan jumlah produk pengolahan sebagai penunjang tambang. Berdasarkan monthly report unit crusher PT Bukit Asam, Tbk., tabel 5 menunjukkan kebutuhan rata-rata batu andesit dari unit crushing plant yang sudah ada.

Tabel 5. Rata-rata kebutuhan batu andesit untuk penunjang tambang saat ini

\begin{tabular}{|l|r|}
\hline Fraksi Crushing Plant I & $\begin{array}{c}\text { Kebutuhan Rata-Rata } \\
\text { (Ton/Bulan) }\end{array}$ \\
\hline $0-20 \mathrm{~mm}$ & $2.166,667$ \\
\hline $20-60 \mathrm{~mm}$ & $2.951,667$ \\
\hline $60-200 \mathrm{~mm}$ & $12.080,000$ \\
\hline
\end{tabular}

Berdasarkan tabel 5, dapat diperkirakan jumlah Produk pengolahan yang dibutuhkan untuk penunjang tambang dari unit pengolahan II. Apabila mengasumsikan kebutuhan produk pengolahan dari unit pengolahan kedua sama dengan kebutuhan batu andesit dari unit crushing plant yang sudah ada, maka perkiraan untuk tiap-tiap produk yang berukuran relatif sama adalah sebesar 10.136,667 ton/bulan. Data detail ditunjukkan pada Tabel 6 berikut:

Tabel 6. Perkiraan kebutuhan batu andesit dari unit pengolahan II sebagai penunjang tambang

\begin{tabular}{|l|r|}
\hline \multicolumn{1}{|c|}{ Fraksi } & Kebutuhan (Ton/Bulan) \\
\hline $0-10 \mathrm{~mm}$ & $2.116,667$ \\
\hline $10-20 \mathrm{~mm}$ & $2.116,667$ \\
\hline $20-50 \mathrm{~mm}$ & $2.951,667$ \\
\hline $50-70 \mathrm{~mm}$ & $2.951,667$ \\
\hline Jumlah & $10.136,667$ \\
\hline
\end{tabular}

Unit crushing plant II diharapkan dapat memproduksi batu andesit sebanyak 200 ton/jam, sehingga dengan rencana waktu kerja selama 12 jam/hari dapt menghasilkan produk pengolahan sebesar 59.760 ton/bulan. Dengan kebutuhan batu andesit untuk penunjang tambang sebanyak 10.136,667 ton/bulan, akan menyisakan batu andesit sebanyak 49.623,333 ton/bulan. Jumlah inilah yang akan dikomersilkan. Tabel 7 menunjukan perkiraan jumlah tiap-tiap fraksi produk pengolahan unit crushing plant II yang dapat dikomersilkan.

Tabel 7. Jumlah tiap-tiap fraksi pengolahan yang dapat dikomersikan dari unit pengolahan II

\begin{tabular}{|l|r|}
\hline \multicolumn{1}{|c|}{ Produk } & \multicolumn{1}{|c|}{ Jumlah (Ton/Bulan) } \\
\hline $0-10 \mathrm{~mm}$ & $1.362,086$ \\
\hline $10-20 \mathrm{~mm}$ & $6.455,973$ \\
\hline $20-50 \mathrm{~mm}$ & $14.939,061$ \\
\hline $50-70 \mathrm{~mm}$ & $26.866,212$ \\
\hline Jumlah & $49.623,333$ \\
\hline
\end{tabular}


Agar produksi batu andesit berjalan lancar dan normal, diperlukan biaya pengolahan yang dapat menjamin proses tersebut. Besar kecilnya biaya pengolahan dipengaruhi oleh rancangan serta banyaknya alat yang dipakai. Semakin beragam komponen alat yang dirancang dalam unit pengolahan, maka akan semakin besar juga biaya pengolahannya. Biaya pengolahan terdiri dari biaya kepemilikan (owning cost) dan biaya operasional (operating cost).

Biaya kepemilikan (owning cost) merupakan biaya yang ditanggung oleh perusahaan, ketika perusahaan memutuskan untuk memiliki alat berat dengan berbagai alternatif yang ada. Biaya kepemilikan pada unit crushing plant meliputi:

1. Depresiasi

Nilai sisa alat crushing plant pada akhir tahun ekonomis alat selama 5 tahun adalah sebesar 10\% dari harga awal pembelian alat. Harga keseluruhan alat pada unit crushing plant adalah sebesar Rp 13.500.000.000,00 maka dengan melakukan perhitungan menggunakan pers. (1). biaya depresiasi yang harus dikeluarkan adalah sebesar Rp 2.405.700.000,00/tahun.

\section{Bunga (Interest)}

Tarif owning cost untuk bunga modal berdasarkan keputusan bank Indonesia adalah sebesar 3,75\% dari biaya annual tahunan rata-rata (average annual investment). Biaya annual tahunan rata-rata sebesar Rp 2.960.575.455/tahun dikeluarkan selama umur ekonomis alat, yakni 5 tahun. Maka, dengan menggunakan pers. (2), diperoleh biaya bunga (interest) sebanyak Rp 22.204.315,91/tahun.

\section{Pajak (Tax)}

Biaya pajak dibebankan pada biaya annual tahunan ratarata (average annual investment) dari alat berat yang dimiliki oleh perusahaan. Akan tetapi, sejak keputusan MK berlaku tanggal 10 Oktober 2020 alat berat tidak lagi dikenakan biaya pajak. Oleh karena itu, biaya kepemilikan untuk pajak tidak masuk dalam perhitungan biaya pengolahan.

\section{Asuransi}

Untuk mengurangi risiko kerusakan alat berat akibat kecelakaan, diperlukan asuransi yang dapat menanggung semua jenis kecelakaan, yakni asuransi semua risiko (all risk). Besarnya premi asuransi ini ialah $1 \%$ dari biaya annual tahunan rata-rata $\mathrm{Rp} 2.960 .575 .455 /$ tahun dari pembelian alat berat berdasarkan ketetapan PT Asuransi Bina Dana Arta di awal tahun 2020. Dengan penggunaan ekonomis alat selama 5 tahun, biaya asuransi yang harus ditanggung berdasarkan perhitungan menggunakan pers. (2) ialah sebesar Rp 5.921.150,91/tahun.

Besarnya biaya kepemilikan yang harus ditanggung perusahaan ialah $\mathrm{Rp} 2.433 .825 .466,82 /$ tahun. Tabel 8 menunjukan rekapitulasi biaya kepemilikan pada unit crushing plant.
Tabel 8. Owning cost untuk biaya pengolahan

\begin{tabular}{|c|c|c|}
\hline No. & $\begin{array}{c}\text { Komponen Owning } \\
\text { Cost }\end{array}$ & Owning Cost Per Tahun \\
\hline 1. & Depresiasi & $\mathrm{Rp} 2.405 .700 .000,00$ \\
\hline 2. & Bunga (Interest) & $\begin{array}{ll}\mathrm{Rp} & 22.204 .315,91 \\
\end{array}$ \\
\hline 3. & Pajak (Tax) & 0,00 \\
\hline 4. & Asuransi & $5.921 .150,91$ \\
\hline & Total & $\operatorname{Rp} 2.433 .825 .466,82$ \\
\hline
\end{tabular}

Waktu kerja alat adalah selama $4320 \mathrm{jam} /$ tahun, maka biaya biaya kepemilikan sebesar Rp 563.385,52/jam.

Biaya operasional (operational cost) merupakan keseluruhan biaya yang harus ditangguhkan perusahaan untuk menjamin produksi unit crushing plant berjalan secara normal tanpa hambatan. Biaya operasional (operational cost) pada unit crushing plant meliputi:

1. Listrik

Kebutuhan listrik pada unit crushing plant adalah 24.625 $\mathrm{kWh} /$ bulan dengan jam kerja 98,5 jam. Harga listrik yang ditetapkan pemerintah untuk pelaku industri adalah sebesar Rp 996,74/kWh. Maka, dengan menggunakan pers. (4), dapat dihitung biaya penggunaan listrik pada unit pengolahan adalah $\mathrm{Rp}$ 24.544.722,5/bulan. Sedangkan biaya penggunaan listrik dalam satu jam adalah Rp 249.185/jam.

\section{Pelumas dan Gemuk}

Penggunaan oli sebagai bahan pelumasan pada unit pengolahan ialah sebanyak $0,1595 \mathrm{~L} / \mathrm{jam}$. Apabila harga oli saat ini adalah Rp 62.857,14/L, maka dengan menggunakan pers. (5) dapat diketahui biaya pemakaian oli per jamnya sebesar Rp 10.025,71/jam. Selain oli, diperlukan juga penggemukan pada komponen alat unit pengolahan. Kebutuhan gemuk untuk unit pengolahan adalah sebanyak $0,6439 \mathrm{~kg} / \mathrm{jam}$. Apabila harga gemuk per kilogram dijual sebesar Rp $52.187,5 / \mathrm{kg}$, maka dengan menggunakan pers. (5), biaya yang harus dikeluarkan untuk penggemukan unit crushing plant adalah sejumlah Rp 33.603,53 /Jam. Total biaya dalam pelumasan dan penggemukan unit crushing plant yang harus ditanggung ialah Rp 43.629,24/jam.

\section{Reparasi}

Total biaya reparasi alat yang harus dikeluarkan selama umur ekonomis alat ialah sebesar $90 \%$ biaya pembelian alat. Untuk perhitungan, faktor perbaikan yang digunakan adalah 0,9. Biaya keseluruhan untuk pembelian alat pada unit pengolahan adalah sebesar Rp 13.500.000.000, dengan pemakaian ekonomis alat selama 5 tahun. Berdasarkan perhitungan menggunakan pers. (6), dapat diketahui besarnya biaya reparasi adalah Rp 607.500,00/jam.

\section{Gaji operator}

Terdapat tiga orang pekerja pada unit pengolahan, satu orang operator utama dan dua orang lagi sebagai 
pembantu pekerjaan operator. Sesuai dengan ketetapan pemerintah kabupaten Muara Enim mengenai upah minimum sektoral, gaji operator ialah $\mathrm{Rp}$ 3.158.277/bulan. Keseluruhan biaya yang harus dikeluarkan sebagai upah operator ialah sebesar Rp 9.474.831/bulan. Waktu kerja operator ialah 360 jam/bulan, maka dengan perhitungan menggunakan pers. (7) dapat diketahui biaya pengeluaran untuk upah operator adalah Rp 26.318,98/jam.

Biaya operasional yang harus dikeluarkan perusahaan agar terjaminnya proses produksi adalah sebesar Rp 926.633,22/jam. Tabel 9 berikut merupakan rekapitulasi biaya operasional unit crushing plant.

Tabel 9. Operating cost untuk unit pengolahan

\begin{tabular}{|c|l|c|}
\hline No. & $\begin{array}{c}\text { Komponen Operating } \\
\text { Cost }\end{array}$ & $\begin{array}{c}\text { Operating Cost Per } \\
\text { Jam }\end{array}$ \\
\hline 1. & Listrik & $\operatorname{Rp} 249.185,00$ \\
\hline 2. & Pelumas dan Gemuk & $\operatorname{Rp~} 43.629,24$ \\
\hline 3. & Reparasi & $\operatorname{Rp} 607.500,00$ \\
\hline 4. & Gaji Operator & $\operatorname{Rp~} 26.318,98$ \\
\hline \multicolumn{2}{|c|}{ Total } & $\operatorname{Rp~} 926.633,22$ \\
\hline
\end{tabular}

Total biaya pengolahan batu andesit adalah sebesar Rp $1.490 .018,74 / \mathrm{jam}$.

Investasi crushing plant baru membutuhkan biaya yang tidak sedikit, sehingga perlu dilakukan perhitungan keuntungan yang akan diperoleh oleh perusahaan. Perhitungan keuntungan dapat dilakukan dengan menghitung banyaknya produksi batu andesit hasil pengolahan dengan harga jual. Tabel 10 berikut ini merupakan harga jual batu andesit (batu pecah crusher II) berdasarkan Keputusan Gubernur Sumatera Selatan No.801/KPTS/DESDM/2018 untuk kabupaten Muara Enim.

Tabel 10. Harga komoditas batu pecah crusher II

\begin{tabular}{|l|c|c|}
\hline \multicolumn{1}{|c|}{ Batu pecah crusher II } & Satuan & $\begin{array}{c}\text { Harga Satuan } \\
(\mathrm{Rp})\end{array}$ \\
\hline Ukuran $(0-1 \mathrm{~cm})$ & $\mathrm{m}^{3}$ & 170.000 \\
\hline Ukuran $(1-2 \mathrm{~cm})$ & $\mathrm{m}^{3}$ & 160.000 \\
\hline Ukuran $(2-5 \mathrm{~cm})$ & $\mathrm{m}^{3}$ & 135.000 \\
\hline Ukuran $(5-7 \mathrm{~cm})$ & $\mathrm{m}^{3}$ & 135.000 \\
\hline
\end{tabular}

Berdasarkan banyaknya produksi batu andesit hasil pengolahan sebesar Rp 49.623,333 ton/bulan, maka pendapatan yang akan diperoleh perusahaan sebesar Rp 2.763.288.862/ bulan. Tabel 11 menunjukan rincian pendapatan perusahaan dari penjualan masing-masing batu andesit hasil pengolahan unit crushing plant II
Tabel 11. Pendapatan perusahaaan dari penjualan batu andesit hasil pengolahan unit crushing plant II

\begin{tabular}{|c|c|c|c|c|}
\hline Produk & $\begin{array}{c}\text { Produksi } \\
\text { (Ton/Bulan) }\end{array}$ & $\begin{array}{l}\text { Produksi } \\
\left(\mathrm{m}^{3} / \text { Bulan }\right)\end{array}$ & $\begin{array}{c}\text { Harga } \\
\text { jual } / \mathrm{m}^{3}\end{array}$ & Pendapatan/bulan \\
\hline $0-10 \mathrm{~mm}$ & $1.362,086$ & 544,834 & 170.000 & 92.621 .848 \\
\hline $10-20 \mathrm{~mm}$ & $6.455,973$ & $2.582,389$ & 160.000 & Rp 413.182 .272 \\
\hline $20-50 \mathrm{~mm}$ & $14.939,061$ & $5.975,624$ & 135.000 & Rp $\quad 806.709 .294$ \\
\hline $50-70 \mathrm{~mm}$ & $26.866,212$ & $10.746,485$ & 135.000 & Rp 1.450.775.448 \\
\hline \multicolumn{4}{|c|}{ Total Pendapatan } & $\operatorname{Rp} 2.763 .288 .862$ \\
\hline
\end{tabular}

Biaya pengolahan yang harus ditanggung oleh perusahaan adalah sebesar Rp 1.490.018,74/jam. Waktu produksi unit crushing plant II adalah 12 jam/hari, dalam waktu 30 hari. Maka, dengan pendapatan yang masuk dari penjualan batu andesit hasil pengolahan sebesar Rp 2.763.288.862/bulan, perusahaan akan memperoleh keuntungan kotor sebesar Rp 2.271.582.678/bulan. Tabel 12 menampilkan rincian keuntungan kotor yang diperoleh perusahaan.

Tabel 12. Keuntungan penjualan batu andesit hasil pengolahan unit crushing plant II

\begin{tabular}{|c|c|c|c|}
\hline $\begin{array}{c}\text { Pendapatan per } \\
\text { bulan }\end{array}$ & $\begin{array}{c}\text { Biaya } \\
\text { pengolahan } \\
\text { per jam }\end{array}$ & $\begin{array}{c}\text { Biaya } \\
\text { pengolahan per } \\
\text { bulan }\end{array}$ & $\begin{array}{c}\text { Keuntungan } \\
\text { per bulan }\end{array}$ \\
\hline $\begin{array}{c}\text { Rp } \\
2.763 .288 .862 \\
\text { /bulan }\end{array}$ & $\begin{array}{c}\text { Rp } \\
1.490 .018,74 \\
\text { /jam }\end{array}$ & $\begin{array}{c}\text { Rp 491.706.184 } \\
\text { /bulan }\end{array}$ & $\begin{array}{c}\text { Rp } \\
2.271 .582 .678 \\
\text { /bulan }\end{array}$ \\
\hline
\end{tabular}

\section{KESIMPULAN}

Dalam perancangan alur kerja pengolahan batu andesit diperlukan penambahan unit peremukan kedua yakni berupa secondary jaw crusher serta menambahkan vibrating screen dengan 3 buah deck supaya kualitas produk hasil pengolahan dapat memenuhi standar. Produk hasil pengolahan yang diperoleh adalah batu andesit dengan ukuran 0-10mm, 10-20mm, 20-50mm dan 50-70mm. Dari florchart pengolahan tersebut diperkirakan 49.623,333 ton/bulan batu andesit hasil pengolahan dapat dikomersilkan.

Investasi untuk unit crushing plant membutuhkan biaya yang cukup besar. Berdasarkan kemungkinan banyaknya produk pengolahan batu andesit yang dapat dihasilkan, perusahaan akan mendapatkan keuntungan kotor sebesar Rp 2.271.582.678/bulan.

\section{DAFTAR PUSTAKA}

[1] Amdi, M. D., Mukiat, dan Ningsih, Y. B., (2020). Kajian Pengolahan Batuan Andesit untuk Mendapatkana Kualitas Produk Menurut Standar Industri Indonesia di PT Bukit Asam Tbk. Tanjung Enim, Sumatera Selatan. Skripsi, 
Fakultas Teknik, Teknik Pertambangan Universitas Sriwijaya

[2] Purwati, A, As'ad, S., dan Sunarmasto, (2014). Pengaruh Ukuran Butiran Agregat Terhadap Kuat Tekan dan Modulus Elastisitas Beton Kinerja Tinggi Grade 80. E-Jurnal Matriks Teknik Sipil, 2(2): 58-6.

[3] Besouw, G. V., Manoppo, M. R. E. dan Palenewen, S. C. N., (2019). Pengaruh Modulus Kehalusan Agregat terhadap Penentuan Kadar Aspal pada Campuran Jenis AC-WC. Jurnal Sipil Statik, 7(4): 483-489.

[4] Fladvad, M. dan Onnela, T., (2020). Influence of jaw crusher parameters on the quality of primary crushed aggregates. Elseiver, 151 (106338): 1-2.

[5] Putra, R.S., Pulungan, L. dan Muchsin, A.M., (2018). Evaluasi Kinerja Unit Alat Peremuk (Crusher) Batuan Andesit di PT Sinar Mandiri Mitrasejati, Desa Rengasjajar, Kecamatan Cigudeg, Kabupaten Bogor, Provinsi Jawa Barat, Prosiding Teknik Pertambangan, Bandung: Fakultas Teknik.

[6] Nugraha, S., Widayati, S. dan Yuliadi, (2018). Upaya Peningkatan Produksi (Split) Batu Andesit dengan Metode Perubahan CSS (Closed Side Setting) pada Crushing Plant di PT Panghear Mitra Abadi Desa Lagadar, Kecamatan Margaasih, Kabupaten Bandung, Provinsi Jawa Barat, Prosiding Teknik Pertambangan, Bandung: Fakultas Teknik.

[7] Boyd, K., (2016). Crushing Plant Design and Layout Considerations. AMEC Mining \& Metals.

[8] Omiyale, B. O., Adebiyi, K. A., dan Raheem, W.A., (2018). Safety Considerattion in the Development of Improved Stone Jaw Crushe for Quarry Operations. International Journal of Engineering Research \&Technology (IJERT). 7(6): 306-307.

[9] Susanto, D. P. R., (2019). Kajian Teknis Produktivitas Unit Peremukan Batu Andesit di PT Gawi Maju Kabupaten Purworejo Provinsi Jawa Tengah. Skripsi, Teknik Pertambangan: Universitas Pembangunan Nasional "Veteran" Yogyakarta.

[10] Monalisa, (2018). Studi Kelayakan Ekonomis Penambangan dan Pengolahan Bahan Galian Basalt menjadi Batu Split di Area Bukit Karang Putih PT Semen Padang. Skripsi, Fakultas Teknik: Universitas Negeri Padang.

[11] Millops, (2020). AMIT 135: Lesson 5 Crushing. (https://millops.community.uaf.edu/amit-135/ amit-135-lesson-5/) diakses April 2020.

[12] Sumardi, E., Zaenal, Widiyati, S., (2017). Kajian Biaya Kepemilikan (Owning Cost) dan Biaya Operasi (Operating Cost) pada Peralatan Penambangan Batuan Andesit di PT Panghegar Mitra Abadi, Blok Gunung Gadung, Kampung Cikuya Desa Lagadar, Kecamatan Margaasih, Kabupaten Bandung Provinsi Jawa Barat.
Prosiding Teknik Pertambangan, Bandung: Fakultas Teknik.

[13] Rumengan, M. R., Dundu, A. K. T., Pratasis, P. A. K., (2017). Analisa Kelayakan Investasi Alat Berat Stone Crusher di Kelurahan Kumersot Kota Bitung. Jurnal Sipil Statik, 5(10): 680-681.

[14] Giatman, M., (2011). Ekonomi Teknik. Jakarta: PT RajaGrafindo Persada.

[15] Tripoli, B., Febrianti, D. dan Musliadi, (2018). Analisa pemakaian alat berat Excavator dengan Straight Line dan Reducing Charge Method. Jurnal Universitas Teuku Umar, 4(2): 84-86.

[16] Dania, P., Widayati, S. dan Zaenal, (2018). Evaluasi Biaya Kepemilikan (Owning Cost) dan Biaya Operasi (Operating Cost) Dump Truck Hino Ranger FF 173 MA pada Penambangan Batu Andesit di CV Panghegar, Blok Gunung Patapaan Desa Cilalawi, Kecamatan Sukatani, Kabupaten Purwakarta, Provinsi Jawa Barat. Prosiding Teknik Pertambangan, Bandung: Fakultas Teknik. 